\title{
SISTEM PENGAMBILAN KEPUTUSAN DALAM PEMILIHAN MERK SMARTPHONE ANDROID TERBAIK DIKALANGAN MAHASISWA UNIVERSITAS PAMULANG DENGAN MENGGUNAKAN METODE TOPSIS
}

\author{
Ilmadi $^{1,}$ a), Desi Natalia Muskananfola ${ }^{2, b)}$ \\ ${ }^{1}$ Program Studi Matematika FMIPA Universitas Pamulang \\ ${ }^{2}$ Program Studi Matematika FMIPA Universitas Pamulang \\ Email: ${ }^{a}$ il.ilmadi@yahoo.com, ${ }^{\text {b) }}$ desinataliamfola@ gmail.com
}

\begin{abstract}
This research was conducted based on the desire to know the best Android smartphone among students. One way to find out the best Android smartphone criteria is the TOPSIS method (Technique for Order Preference by Similarity to Ideal Solution). The data used are primary data from the result of filing out questionnaires by Mathematics Faculty Students and Natural Science. The result showed that the selection of the best Android Smartphone type among student with the Topsis method with the largest value of 0.77, Xiaomi Mi Max 2 with value of 9.8, then followed by Vivo V9 with a value of 0.77, Xiaomi Mi Max 2 with a value of 0.28, and Asus Zenfone Max Plus (M1). So that Oppo F7 is the best Android Smartphone.
\end{abstract}

Keywords : Alternative, Criteria, Method, Android, Topsis

Abstrak

Penelitian ini dilakukan dengan dilatarbelakangi oleh keinginan untuk mengetahui smartphone android terbaik dikalangan mahasiswa. Salah satu cara untuk mengetahui kriteria smartphone android terbaik adalah dengan metode TOPSIS (Technique for Order Preference by Similarity to Ideal Solution). Data yang digunakan adalah data primer dari hasil pengisian kuisioner oleh Mahasiswa Fakultas Matematika dan Ilmi Pengetahuan Alam. Hasil Penelitian menunjukan bahwa pemilihan Tipe Smartphone android terbaik dikalangan Mahasiswa dengan metode Topsis dengan nilai terbesar yang diperoleh oleh Oppo F7 dengan nilai sebesar 0,98, kemudian diikuti Vivo V9 dengan nilai sebesar 0,77, Xiaomi Mi Max 2 dengan nilai sebesar 0,28, dan Asus Zenfone Max Plus (M1). Sedemikian sehingga Oppo F7 merupakan smartphone android terbaik

Kata Kunci : Alternatif, Kriteria, Metode, Android, Topsis

\section{PENDAHULUAN}

Kebutuhan akan komunikasi yang fleksibel menuntut setiap individu untuk memiliki smartphone. Oleh sebab itulah, para produsen semakin tekun memproduksi smartphone dengan berbagai pembaruan sistem serta fitur-fitur yang canggih. Mulai dari sisi kamera, desain, layar, hingga jeroannya terus mengalami peningkatan. Smartphone yang memiliki banyak peminat sepanjang tahun 2018 yakni Vivo, Oppo, Xiaomi, dan Asus.

Perkembangan smartphone yang semakin meningkat ini baik dari desain yang menarik maupun dari fitur yang canggih, menuntut setiap individu agar lebih selektif 
dalam menentukan pemilihan pembelian smartphone android terbaik yang sesuai dengan kebutuhannya. Namun dalam menentukan pemilihan pembelian merksmartphone android yang sesuai dengan kebutuhan konsumen karena begitu banyak merkhandphone yang ditawarkan.

Sistem pendukung Keputusan (SPK) secara umum didefinisikan sebagai sebuah system yang mampu menghasilkan pemecahan maupun penanganan masalah. SPK tidak dimaksudkan untuk menggantikan peran pengambilan keputusan, tapi untuk membantu dan mendukung dalam pengambilan keputusan.

Dalam pemilihan smartphone android banyak juga pertimbangan-pertimbangan yang harus diperhatikan oleh customer seperti : harga, kualitas jaringan, kapasitas memori, kapasitas RAM dan sensor lock android. Pertimbangan ini dilakukan agar customer lebih fokus dalam pemilihansmartphone android terbaik, sehingga dapat diketahui smartphone mana yang lebih cenderung banyak diminati.

Selain itu dalam pemilihan smartphone android ini yang digunakan adalah merk smartphone android yang sedang popular di tahun 2018, dan alternatif yanghanya dipilih dalam pemilihan smartphone android ini adalah Vivo V9, Asus zenfone Max Plus (M1), Xiaomi Mi Max 2, Oppo F7. Metode yang bisa digunakan untuk mengatasi masalah pemilihan alternative terbaik adalah Multi-Altribut Decision Making (MADM). Metode MADM terdiri dari lima jenis metode, yaitu Simple Additive Weighting (SAW), Weighted Product (WP), Elmination Et Choix Traduisant la Realite (ELECTRE), Technique for Order Preference by Similarity to Ideal Solution (TOPSIS) dan Analytic Hierarchy Process (AHP).

Metode yang dipakai pada penelitian diatas yakni Technique for Order Preference by Similarity to Ideal Solution (TOPSIS). "Metode TOPSIS merupakan bentuk metode pendukung keputusan yang didasarkan pada konsep bahwa alternatif yang terbaik tidak hanya memiliki jarak terpendek dari solusi ideal positif tetapi juga memiliki jarak terpanjang dari solusi ideal negatif. Solusi ideal positif diperoleh dari nilai maksimum matriks keputusan ternormalisasi terbobot jika kriteria merupakan kerugian. Sebaliknya, solusi ideal negatif diperoleh dari nilai minimum matriks keputusan ternormalisasi terbobot jika kriteria yang merupakan keuntungan dan nilai maksimum matriks keputusan ternormalisasi terbobot jika kriteria merupakan kerugian." (Defit, 2017)

Penilitian ini berdasarkan ada beberapa penelitian terdahulu yaitu penerapan dengan metode TOPSIS yang sudah dilakukan oleh (Maulana,2016) yang melakukan penelitian tentang penerimaan calon karyawan baru menggunakan metode TOPSIS yang dibuktikan bahwa metode TOPSIS bisa dugunakan dan tepat untuk menyelesaikan masalah multi dimensi walaupun banyak criteria komponen penelitian pada setiap alternative. Kemudian penelitian mengenai system pendukung keputusan dalam pemilihan smartphone sudah pernah dilakukan. Penelitian tersebut yang silakukan oleh penelitian terdahulu dengan menggunakan dua metode yaitu Technique for Order Preference by Similarity to Ideal Solution (TOPSIS) dan Analytic Hierarchy Procces (AHP).

Metode AHP biasanya digunakan untuk menentukan bobot kepentingan sedangkan metode TOPSIS yang digunakan pada penelitian terdahulu lebih digunakakan untuk menentukan perangkingan smartphone terbaik. Hasil dari penelitian tersebut adalah system yang dibangun mampu memberikan perangkingan handphone terbaik yang sesuai dengan kriteria yang dipilih oleh pengguna. Hal tersebut yang mendasari penulis untuk melakukan penelitian mengenai "Sistem Pengambilan Keputusan dalam Pemilihan Merk Smartphone Android Terbaik dikalangan Mahasiswa Universitas Pamulang Menggunakan Metode TOPSIS (Technique for Order Preference by Similarity to Ideal Solution)". 


\section{METODE PENELITIAN}

Penelitian ini menggunakan metode kuantitatif. Metode ini sebagai metode ilmiah karena telah memenuhi kaidah-kaidan ilmiah yaitu konkrit (empiris), obyektif, terukur, rasional dan sistematis. Digunakan untuk meneliti pada populasi atau sampel tertentu, pengumpulan dan menggunakan instrument penelitian, analisis data bersifat statistic dengan tujuan untuk menguji hipotesis yang telah ditetapkan. Proses penelitian bersifat deduktif, dimana untuk menjawab rumusan masalah digunakan konsep atau teori sehingga dapat dirumuskan hipotesis.

Penelitian ini dilakukan di Universitas Pamulang Bulan November 2018. Adapun yang menjadi populasi dalam penelitian ini adalah Mahasiswa Fakultas Matematika dan Ilmu Pengetahuan Alam Universitas Pamulang. Teknik pengumpulan data dalam penelitian ini dilakukan dengan cara 1) Observasi, Observasi digunakan untuk memperoleh data yaitu pengamatan terhadap mahasiswa Fakultas Matematika dan Ilmu Pengetahuan Alam untuk melihat penggunaan smartphone android dikalangan mahasiswa. 2) Kuesioner, kuesioner ini diisi oleh mahasiswa Fakultas Matematika dan Ilmu Pengetahuan Alam Universitas Pamulang. Variabel Kriteria yang digunakan yaitu : Harga, Kualitas Jaringan, Kualitas Memori, Kualitas RAM, dan Sensor Lock Screen. Sedangkan untuk variabel alternative adalah Vivo V9, Asus Zenfone Max Plus (M1), Xiaomi Mi Max 2, dan Oppo F7. 3). Studi Pustaka. tekhnik ini dilakukan dengan mencari literathur dan referensi dari buku-buku bacaan yang mengandung teori, keterangan atau laporan yang berhubungan dengan penelitian ini.

Teknik Pengolahan data dilakukan mengikuti tahapan pada metode TOPSIS. Berikut ini adalah tahapan-tahapan dalam pengolahan data: 1). Menentukan kriteria dan alternative dalam menentukan smartphone yang akan digunakan. 2). Menentukan pembobotan kriteria atau bobot keputusan. 3). Membuat matriks yang menggambarkan kontribusi atau pengaruh setiap alternatif atas setiap kriteria. Perbandingan dilakukan berdasarkan penilaian dari pengambilan keputusan dengan menilai tingkat kepentingan suatu alternatif. 4). Menentukan matriks keputusan yang ternormalisasi dan matriks keputusan yang telah dibuat. 5). Menentukan matriks keputusan yang ternormalisasi terbobot dan matriks keputusan yang ternormalisasi. 6). Menentukan solusi ideal positif dan solusi ideal negatif dari matriks keputusan yang ternormalisasi terbobot dengan mengidentifikasi nilai maksimum atau nilai minimum berdasarkan kriteria keuntungan (benefit criteria) atau kriteria biaya (cost criteria) terhadap masing-masing kriteria. 7). Menentukan separasi atau jarak pendekatan antara nilai setiap alternatif. 8). Menentukan nilai preferensi untuk setiap alternatif.” (Pratiwi, 2016)

\section{HASIL DAN PEMBAHASAN}

\section{1) Perhitungan Pembobotan Komponen untuk Semua Kriteria}

Langkah yang akan dilakukan pertama ialah pembobotann dari semua kriteria. Pembobotan dilakukan oleh mahasiswa Fakultas Matematika dan Ilmu Pengetahuan Alam Universitas Pamulang. Menghitung nilai dari kriteria kedalam tabel PCM :

$$
\begin{aligned}
& R_{11}=R_{22}=R_{33}=R_{44}=R_{55}=1 \\
& R_{12}, R_{13}, R_{14}, R_{15}, R_{23}, R_{24}, R_{25}, R_{34}, R_{35}, R_{45} \text { di peroleh dari kuisioner. } \\
& R_{21}=\frac{R_{11}}{R_{12}}=\frac{1}{2}=0,5 \quad ; R_{31}=\frac{R_{11}}{R_{18}}=\frac{1}{2}=0,5 \quad ; \text { dan seterusnya }
\end{aligned}
$$


Hasil pembobotan pada masing-masing kriteria yang sudah diperoleh, diolah, kemudian ditulis ke dalam table PCM seperti yang terlihat pada Tabel 1

Tabel 1 PCM Gabungan Untuk Semua Kriteria

\begin{tabular}{lccccc}
\hline \multicolumn{1}{c}{ Kriteria } & Harga & $\begin{array}{c}\text { Kualitas } \\
\text { Jaringan }\end{array}$ & $\begin{array}{c}\text { Kapasitas } \\
\text { Memori }\end{array}$ & Kapasitas RAM & Sensor Lock \\
\hline Harga & 1,00 & 2,00 & 2,00 & 2,00 & 4,00 \\
$\begin{array}{l}\text { Kualitas } \\
\text { Jaringan }\end{array}$ & 0,50 & 1,00 & 3,00 & 4,00 & 5,00 \\
Kapasitas & 0,50 & 0,33 & 1,00 & 2,00 & 4,00 \\
Memori & & 0,25 & 0,20 & 1,00 & 2,00 \\
Kapasitas RAM & 0,50 & 0,20 & 0,25 & 0,50 & 1,00 \\
Sensor Lock & 0,25 & 0,25 & 12,50 & 16,00 \\
Total & 2,75 & 3,78 & 6,45 & & \\
\hline
\end{tabular}

Setelah nilai pada tabel PCM gabungan untuk semua kriteria sudah diketahui, maka matriks dinormalisasikan dengan cara membagi setiap entri Tabel 1 dengan total masing-masing kolom sebagai berikut:

$N_{11}=\frac{R_{11}}{R_{61}}=\frac{1}{2,75}=0,36 ; N_{31}=\frac{R_{81}}{R_{61}}=\frac{0,5}{2,75}=0,18 ; N_{51}=\frac{R_{51}}{R_{61}}=\frac{0,75}{2,75}=0,09$
$N_{21}=\frac{R_{21}}{R_{61}}=\frac{0,5}{2,75}=0,18 ; N_{41}=\frac{R_{41}}{R_{61}}=\frac{0,5}{2,75}=0,18 ;$ dan seterusnya

Tabel 2 Normalisasi PCM

\begin{tabular}{lcccccc}
\hline \multicolumn{1}{c}{ Kriteria } & Harga & $\begin{array}{c}\text { Kualitas } \\
\text { Jaringan }\end{array}$ & $\begin{array}{c}\text { Kapasitas } \\
\text { Memori }\end{array}$ & $\begin{array}{c}\text { Kapasitas } \\
\text { RAM }\end{array}$ & Sensor Lock & $\begin{array}{c}\text { Row } \\
\text { Average }\end{array}$ \\
\hline Harga & 0,36 & 0,53 & 0,30 & 0,21 & 0,25 & 0,33 \\
$\begin{array}{l}\text { Kualitas } \\
\text { Jaringan }\end{array}$ & 0,18 & 0,26 & 0,44 & 0,42 & 0,31 & 0,32 \\
$\begin{array}{l}\text { Kapasitas } \\
\text { Memori }\end{array}$ & 0,18 & 0,09 & 0,15 & 0,21 & 0,25 & 0,18 \\
$\begin{array}{l}\text { Kapasitas RAM } \\
\text { Sensor Lock }\end{array}$ & 0,18 & 0,07 & 0,07 & 0,11 & 0,13 & 0,11 \\
$\quad$ Total & 1,09 & 0,05 & 0,04 & 0,05 & 0,06 & 0,06 \\
& 1,00 & 1,00 & 1,00 & 1,00 & 1,00 \\
\hline
\end{tabular}

Untuk masing-masing kriteria dalam pemilihan smartphone android,yaitu kriteria harga sebedar 0,33, kualitas jaringan sebesar 0,32, kapasitas memori sebesar 0,18kapasitas RAM sebesar 0,11, dan sensor lock sebesar 0,06. Jika sudah diperoleh nilai dari masing-masing kriteria, langkah berikutnya yakni menguji konsistensi dan menghitung (weighted Sum Vector Consistency) kemudian mencari nilai $\lambda$, CI dan CR. Weighted Sum Vector Consistency (WSV) diperoleh dengan cara sebagai berikut : Weighted Sum Vector Consistency (Tabel. 1 x Row average Tabel 2) 


$\left[\begin{array}{l}1,002,002,002,004,00 \\ 0,501,003,004,005,00 \\ 0,500,331,002,004,00 \\ 0,500,250,201,002,00 \\ 0,250,200,250,501,00\end{array}\right]\left[\begin{array}{rr}0,33 \\ 0,32 \\ 0,18 \\ 0,11 \\ 1,75 \\ 0,06\end{array}\right] \begin{array}{r}1,91 \\ 0,56 \\ 0,31\end{array}$

Setelah matriks WSV sudah didapatkan kemudian akan dihitung nilai dari Consistency Vector: Consistency Vector(WSV/Row Average)

$\left[\begin{array}{l}\frac{1,79}{0,33} \\ \frac{1,75}{0,32} \\ \frac{1,91}{0,18} \\ \frac{0,56}{0,11} \\ 0,31 \\ 0,06\end{array}\right]=\left[\begin{array}{l}5,56 \\ 5,79 \\ 5,54 \\ 5,09 \\ 5,29\end{array}\right]$

Setelah consistency Vector sudah ditemukan, maka akandicari nilai $\lambda$ yakni dengan menjumlah consistency vector kemudian dibagi nilai $\mathrm{n}$, dimana $n$ adalah rasio matriks yang bersangkutan. $\lambda=\frac{\sum \text { consistency vector }}{n}=\frac{26,25}{5}=5,25$. Setelah nilai $\lambda$ sudah ditemukan maka berikut mencari nilai CI dan CR dan dapat mengetahui konsistensi dari data yang sudah diperoleh. $\mathrm{CI}=\frac{\lambda-\mathrm{n}}{n-1}=\frac{5,25-5}{5-1}=\frac{0,25}{4}=0,06$. Langkah selanjutnya $\mathrm{CR}$ dihitung dengan membagi nilai CI oleh RI yaitu Ratio Indeks yang diperoleh pada tabel RI. Besarkan RI untuk $\mathrm{n}=5$ adalah $1,12 \mathrm{CR}=\frac{\mathrm{CI}}{R I}=\frac{0,06}{1,12}=0,06$. Nilai dari $\mathrm{CR}$ yang sudah didapatkan $\leq 0,1$ artinya data sudah konsisten. Maka bisa disimpulkan bahwa kriteria yang dipilih dalam pemilihan smartphone androidadalah krieteria harga sebesar $33 \%$, kualitas jaringan sebesar 32\%, kapasitas memori sebesar $18 \%$, kapasitas RAM sebesar $11 \%$, dan sensor locksebesar $6 \%$. Dari setiap bobot yang sudah didapatkan dari setiap kriteria, maka dapat dibentuk bobot preferensi yaitu $\mathrm{W}=(0,33,0,32,0,18,0,11,0,06)$. Bobot preferensi ini digunakan dalam menghitung matriks keputusan ternormalisasi terbobot pada langkah-langkah pemilihan smartphone android.

\section{2) Perhitungan Pembobotan Komponen untuk Masing-masing Kriteria}

Analisis pada tahap ini dilakukan agar mengetahui tingkatan prioritas pada masing-masing alternative terhadap setiap kriteria dalam memilih smartphone android.

\subsection{Perhitungan Pembobotan Komponen untuk Kriteria Harga}

Analisis ini dilakukan agar dapat mengetahui tingkatan dari prioritas masingmasing alternative pada kriteria harga dalam pemilihan smartphone android. Hasil dari pembobotan masing-masing alternative yang didapatkan, diolah kemudian dimasukkan kedalam tabel PCM dengan rumus yang sama dengan Tabel 1. Seperti terlihat pada Tabel 3 berikut 
Tabel 3 PCM untuk Kriteria Harga

\begin{tabular}{lcccc}
\hline \multicolumn{1}{c}{ Harga } & Vivo V9 & Oppo F7 & Xiaomi Mi Max 2 & $\begin{array}{c}\text { Asus Zenfone Max } \\
\text { Plus (M1) }\end{array}$ \\
\hline Vivo V9 & 1,00 & 1,00 & 3,00 & 3,00 \\
Oppo F7 & 1,00 & 1,00 & 3,00 & 3,00 \\
Xiaomi Mi Max 2 & 0,33 & 0,33 & 1,00 & 2,00 \\
Asus Zenfone & 0,33 & 0,33 & 0,50 & 1,00 \\
Max Plus (M1) & & & & 12,00 \\
\hline \multicolumn{1}{c}{ Total } & 2,67 & 2,67 & 7,50 & \\
\hline
\end{tabular}

Setelah diperoleh PCM untuk kriteria harga, matriks dinormalisasikan menggunakan cara yang sama dalam tabel 2 dengan membagi setiap entri pada Tabel 3 dengan total masing-masing kriteria sebagai berikut :

Tabel 4 Normalisasi PCM

\begin{tabular}{lccccc}
\hline \multicolumn{1}{c}{ Harga } & Vivo V9 & Oppo F7 & Xiaomi Mi Max 2 & $\begin{array}{c}\text { Asus Zenfone } \\
\text { Max Plus (M1) }\end{array}$ & $\begin{array}{c}\text { Row } \\
\text { Average }\end{array}$ \\
\hline Vivo V9 & 0,38 & 0,38 & 0,40 & 0,33 & 0,37 \\
Oppo F7 & 0,38 & 0,38 & 0,40 & 0,33 & 0,37 \\
Xiaomi Mi Max 2 & 0,13 & 0,13 & 0,13 & 0,22 & 0,15 \\
$\begin{array}{l}\text { Asus Zenfone } \\
\text { Max Plus (M1) }\end{array}$ & 0,13 & 0,13 & 0,07 & 0,11 & 0,11 \\
\hline \multicolumn{1}{c}{ Total } & 1,00 & 1,00 & 1,00 & 1,00 & 1,00 \\
\hline
\end{tabular}

Dari Tabel 4 diperoleh bobot prioritas (row average) untuk masing-masing alternative terhadap kriteria harga dalam pemilihan smartphone android, yaitu Vivo V9 sebesar 0,37, Oppo F7 sebesar 0,37, Xiaomi Mi Max 2 sebesar 0,15, dan Asus Zenfone Max Plus (M1) sebesar 0,11. Jika sudah diperoleh nilai dari masing-masing kriteria, langkah berikutnya yakni menguji konsistensi dan menghitung (weighted Sum Vector Consistency) kemudian mencari nilai $\lambda$, CI dan CR. Weighted Sum Vector Consistency (WSV) diperoleh dengan cara sebagai berikut : Weighted Sum Vector Consistency (Tabel 3 x Row average Tabel 4)

$\left[\begin{array}{l}1,001,003,003,00 \\ 1,001,003,003,00 \\ 0,330,331,002,00 \\ 0,330,330,501,00\end{array}\right]\left[\begin{array}{l}0,37 \\ 0,37 \\ 0,15 \\ 0,11\end{array}\right]=\begin{array}{r}4,09 \\ 4,09 \\ 4,05 \\ 4,02\end{array}$

Setelah matriks WSV sudah didapatkan kemudian akan dihitung nilai dari Consistency Vector : 


$$
\left[\begin{array}{l}
\frac{1,52}{0,37} \\
\frac{1,52}{0,37} \\
\frac{0,61}{0,15} \\
\frac{0,43}{0,11}
\end{array}\right]=\left[\begin{array}{l}
4,09 \\
4,09 \\
4,05 \\
4,02
\end{array}\right]
$$

Setelah consistency Vector sudah ditemukan, maka akandicari nilai $\lambda$ yakni dengan menjumlah consistency vector kemudian dibagi nilai $\mathrm{n}$, dimana $n$ adalah rasio matriks yang bersangkutan. $\lambda=\frac{\sum \text { consistency vector }}{n}=\frac{16,25}{4}=4,06$. Setelah nilai $\lambda$ sudah ditemukan maka berikut mencari nilai CI dan CR dan dapat mengetahui konsistensi dari data yang sudah diperoleh. $\mathrm{CI}=\frac{\lambda-\mathrm{n}}{n-1}=\frac{4,06-4}{4-1}=\frac{0,06}{3}=0,02$. Langkah selanjutnya $\mathrm{CR}$ dihitung dengan membagi nilai CI oleh RI yaitu Ratio Indeks yang diperoleh pada tabel RI. Besarkan RI untuk $\mathrm{n}=4$ adalah $0,90 . \mathrm{CR}=\frac{\mathrm{CI}}{R I}=\frac{0,02}{0,90}=0,02$. Nilai dari $\mathrm{CR}$ yang sudah didapatkan $\leq 0,1$ artinya data sudah konsisten. Maka bisa disimpulkan bahwa harga yang dipilih dalam pemilihan smartphone Vivo V9 sebesar 37\%, Oppo F7sebesar 37 \%, Xiaomi Mi Max 2 sebesar $15 \%$, dan Asus Zenfone Max Plus (M1) sebesar $11 \%$.

\subsection{Perhitungan Pembobotan Komponen untuk Kriteria Kualitas Jaringan}

Analisis ini dilakukan agar dapat mengetahui tingkatan dari prioritas masingmasing alternative pada kriteria kualitas jaringan dalam pemilihan smartphone android. Hasil dari pembobotan masing-masing alternative yang didapatkan, diolah kemudian dimasukkan kedalam tabel PCM dengan rumus yang sama dengan Tabel, seperti terlihat pada Tabel 5 berikut

Tabel 5 PCM untuk Kriteria Kualitas Jaringan

\begin{tabular}{ccccc}
\hline $\begin{array}{c}\text { Kualitas } \\
\text { Jaringan }\end{array}$ & Vivo V9 & Oppo F7 & Xiaomi Mi Max 2 & $\begin{array}{c}\text { Asus Zenfone Max } \\
\text { Plus (M1) }\end{array}$ \\
\hline $\begin{array}{c}\text { Vivo V9 } \\
\text { Oppo F7 }\end{array}$ & 1,00 & 1,00 & 1,00 & 3,00 \\
Xiaomi Mi Max & 1,00 & 1,00 & 3,00 & 3,00 \\
2 & 0,33 & 1,00 & 2,00 \\
$\begin{array}{c}\text { Asus Zenfone } \\
\text { Max Plus (M1) }\end{array}$ & 0,33 & 0,33 & 0,50 & 1,00 \\
\hline Total & 3,33 & 2,67 & 5,50 & 9,00 \\
\hline
\end{tabular}

Setelah diperoleh PCM untuk kriteria kualitas jaringan, matriks dinormalisasikan menggunakan cara yang sama dalam tabel 2 dengan membagi setiap entri pada Tabel 5 dengan total masing-masing kriteria sebagai berikut : 
Tabel 6 Normalisasi PCM

\begin{tabular}{cccccc}
\hline Kualitas Jaringan & Vivo V9 & Oppo F7 & $\begin{array}{c}\text { Xiaomi Mi } \\
\text { Max 2 }\end{array}$ & $\begin{array}{c}\text { Asus Zenfone Max } \\
\text { Plus (M1) }\end{array}$ & $\begin{array}{c}\text { Row } \\
\text { Average }\end{array}$ \\
\hline Vivo V9 & 0,30 & 0,38 & 0,18 & 0,33 & 0,30 \\
Oppo F7 & 0,30 & 0,38 & 0,55 & 0,33 & 0,39 \\
Xiaomi Mi Max 2 & 0,30 & 0,13 & 0,18 & 0,22 & 0,21 \\
$\begin{array}{c}\text { Asus Zenfone } \\
\text { Max Plus (M1) }\end{array}$ & 0,10 & 0,13 & 0,09 & 0,11 & 0,11 \\
\hline Total & 1,00 & 1,00 & 1,00 & 1,00 & 1,00
\end{tabular}

Dari Tabel 6 diperoleh bobot prioritas (row average) untuk masing-masing alternative terhadap kriteria kualitas jaringan dalam pemilihan smartphone android, yaitu Vivo V9 sebesaR 30\%,Oppo F7sebesar 39\%, Xiaomi Mi Max 2 sebesar 21\%, dan Asus Zenfone Max Plus (M1) sebesar 11\%. Jika sudah diperoleh nilai dari masing-masing kriteria, langkah berikutnya yakni menguji konsistensi dan menghitung (weighted Sum Vector Consistency) kemudian mencari nilai $\lambda$, CI dan CR. Weighted Sum Vector Consistency (WSV) diperoleh dengan cara sebagai berikut : Weighted Sum Vector Consistency (Tabel $5 \times$ Row average Tabel 6)

$\left[\begin{array}{l}1,001,001,003,00 \\ 1,001,003,003,00 \\ 1,000,331,002,00 \\ 0,330,330,501,00\end{array}\right]\left[\begin{array}{l}0,30 \\ 0,39 \\ 0,21 \\ 0,11\end{array}\right] \begin{array}{r}1,21 \\ 1,63 \\ 0,85 \\ 0,44\end{array}$

Setelah matriks WSV sudah didapatkan kemudian akan dihitung nilai dari Consistency Vector:

$\left[\begin{array}{l}\frac{1,21}{0,30} \\ \frac{1,63}{0,39} \\ 0,85 \\ 00,21 \\ 0,44 \\ 0,11\end{array}\right]=\left[\begin{array}{l}4,08 \\ 4,19 \\ 4,09 \\ 4,11\end{array}\right]$

Setelah consistency Vector sudah ditemukan, maka akandicari nilai $\lambda$ yakni dengan menjumlah consistency vector kemudian dibagi nilai $\mathrm{n}$, dimana $n$ adalah rasio matriks yang bersangkutan. $\lambda=\frac{\sum \text { consistency vector }}{n}=\frac{16_{6} 47}{4}=4,12$. Setelah nilai $\lambda$ sudah ditemukan maka berikut mencari nilai CI dan CR dan dapat mengetahui konsistensi dari data yang sudah diperoleh. $\mathrm{CI}=\frac{\lambda-\mathrm{n}}{1}=\frac{4,12-4}{4-1}=\frac{0,12}{3}=0,04$. Langkah selanjutnya $\mathrm{CR}$ 
dihitung dengan membagi nilai CI oleh RI yaitu Ratio Indeks yang diperoleh pada tabel RI. Besarkan RI untuk $\mathrm{n}=4$ adalah $0,90 . \mathrm{CR}=\frac{\mathrm{CI}}{R I}=\frac{0,04}{0,90}=0,04$

Nilai dari CR yang sudah didapatkan $\leq 0,1$ artinya data sudah konsisten. Maka

bisa disimpulkan bahwa kualitas jaringan yang dipilih dalam pemilihan smartphone Vivo V9 sebesar 30\%,Oppo F7 sebesar 39\%, Xiaomi Mi Max 2 sebesar 21\%, dan Asus Zenfone Max Plus (M1) sebesar 11\%.

\subsection{Perhitungan Pembobotan Komponen untuk Kriteria Kapasitas Memori}

Analisis ini dilakukan agar dapat mengetahui tingkatan dari prioritas masingmasing alternative pada kriteria kapasitas memori dalam pemilihan smartphone android. Hasil dari pembobotan masing-masing alternative yang didapatkan, diolah kemudian dimasukkan kedalam tabel PCM dengan rumus yang sama dengan Tabel 1, seperti terlihat pada Tabel 7 berikut

Tabel 7 PCM untuk Kriteria Kapasitas Memori

\begin{tabular}{lcccc}
\hline Kapasitas Memori & Vivo V9 & Oppo F7 & $\begin{array}{c}\text { Xiaomi Mi Max } \\
2\end{array}$ & $\begin{array}{c}\text { Asus Zenfone Max Plus } \\
\text { (M1) }\end{array}$ \\
\hline Vivo V9 & 1,00 & 2,00 & 2,00 & 1,00 \\
Oppo F7 & 0,50 & 1,00 & 3,00 & 2,00 \\
Xiaomi Mi Max 2 & 0,50 & 0,33 & 1,00 & 1,00 \\
Asus Zenfone & 1,00 & 0,50 & 1,00 & 1,00 \\
Max Plus (M1) & & & 7,00 & 5,00 \\
\hline \multicolumn{1}{c}{ Total } & 3,00 & 3,83 & & \\
\hline
\end{tabular}

Setelah diperoleh PCM untuk kriteria kapasitas memori, matriks dinormalisasikan menggunakan cara yang sama dalam tabel 2 dengan membagi setiap entri pada Tabel 7 dengan total masing-masing kriteria sebagai berikut :

Tabel 8 Normalisasi PCM

\begin{tabular}{lccccc}
\hline $\begin{array}{c}\text { Kapasitas } \\
\text { Memori }\end{array}$ & Vivo V9 & Oppo F7 & $\begin{array}{c}\text { Xiaomi Mi } \\
\text { Max 2 }\end{array}$ & $\begin{array}{c}\text { Asus Zenfone } \\
\text { Max Plus (M1) }\end{array}$ & $\begin{array}{c}\text { Row } \\
\text { Average }\end{array}$ \\
\hline Vivo V9 & 0,33 & 0,52 & 0,29 & 0,20 & 0,34 \\
Oppo F7 & 0,17 & 0,26 & 0,43 & 0,40 & 0,31 \\
Xiaomi Mi Max 2 & 0,17 & 0,09 & 0,14 & 0,20 & 0,15 \\
$\begin{array}{l}\text { Asus Zenfone } \\
\text { Max Plus (M1) }\end{array}$ & 0,33 & 0,13 & 0,14 & 0,20 & 0,20 \\
\hline \multicolumn{1}{c}{ Total } & 1,00 & 1,00 & 1,00 & 1,00 & 1,00 \\
\hline
\end{tabular}

Dari Tabel 8 diperoleh bobot prioritas (row average) untuk masing-masing alternative terhadap kriteria kapasitas memori dalam pemilihan smartphone android, yaitu Vivo V9 sebesar 0,34, Oppo F7 sebesar 0,31, Xiaomi Mi Max 2 sebesar 0,15, dan Asus Zenfone Max Plus (M1) sebesar 0,20 Jika sudah diperoleh nilai dari masing-masing kriteria, langkah berikutnya yakni menguji konsistensi dan menghitung (weighted Sum 
Vector Consistency) kemudian mencari nilai $\lambda$, CI dan CR. Weighted Sum Vector Consistency (WSV) diperoleh dengan cara sebagai berikut : Weighted Sum Vector Consistency (Tabel 7 x Row average Tabel 8)

$\left[\begin{array}{l}1,002,002,001,00 \\ 0,501,003,002,00 \\ 0,500,331,001,00 \\ 1,000,501,001,00\end{array}\right]\left[\begin{array}{l}0,34 \\ 0,31 \\ 0,15 \\ 0,20\end{array}\right] \begin{array}{r}1,46 \\ 1,33 \\ 0,62 \\ 0,84\end{array}$

Setelah matriks WSV sudah didapatkan kemudian akan dihitung nilai dari Consistency Vector

$\left[\begin{array}{l}1,46 \\ 0,34 \\ \frac{1,33}{0,31} \\ 0,62 \\ 0,15 \\ 0,84 \\ 0,20\end{array}\right]=\left[\begin{array}{l}4,37 \\ 4,24 \\ 4,18 \\ 4,18\end{array}\right]$

Setelah consistency Vector sudah ditemukan, maka akandicari nilai $\lambda$ yakni dengan menjumlah consistency vector kemudian dibagi nilai $\mathrm{n}$, dimana $n$ adalah rasio matriks yang bersangkutan. $\lambda=\frac{\sum \text { consistency vector }}{n}=\frac{16,97}{4}=4,24$. Setelah nilai $\lambda$ sudah ditemukan maka berikut mencari nilai CI dan CR dan dapat mengetahui konsistensi dari data yang sudah diperoleh. $\mathrm{CI}=\frac{\lambda-\mathrm{n}}{n-1}=\frac{4,24-4}{4-1}=\frac{0,24}{3}=0,08$. Langkah selanjutnya CR dihitung dengan membagi nilai CI oleh RI yaitu Ratio Indeks yang diperoleh pada tabel RI. Besarkan RI untuk $\mathrm{n}=4$ adalah $0,90 \mathrm{CR}=\frac{\mathrm{CI}}{R I}=\frac{0,08}{0,90}=0,09$. Nilai dari $\mathrm{CR}$ yang sudah didapatkan $\leq 0,1$ artinya data sudah konsisten. Maka bisa disimpulkan bahwa kapasitas memori yang dipilih dalam pemilihan smartphone Vivo V9 sebesar 34\%, Oppo F7 sebesar 31\%, Xiaomi Mi Max 2 sebesar $15 \%$, dan Asus Zenfone Max Plus (M1) sebesar $20 \%$.

\subsection{Perhitungan Pembobotan Komponen untuk Kriteria Kapasitas RAM}

Analisis ini dilakukan agar dapat mengetahui tingkatan dari prioritas masingmasing alternative pada kriteria kapasitas RAM dalam pemilihan smartphone android. Hasil dari pembobotan masing-masing alternative yang didapatkan, diolah kemudian dimasukkan kedalam tabel PCM dengan rumus yang sama dengan Tabel 1, seperti terlihat pada Tabel 9 berikut

Tabel 9 PCM untuk Kriteria Kapasitas RAM

\begin{tabular}{ccccc}
\hline Kapasitas RAM & Vivo V9 & Oppo F7 & $\begin{array}{c}\text { Xiaomi Mi } \\
\text { Max 2 }\end{array}$ & $\begin{array}{c}\text { Asus Zenfone Max } \\
\text { Plus (M1) }\end{array}$ \\
\hline
\end{tabular}




\begin{tabular}{lllll}
\hline Vivo V9 & 1,00 & 1,00 & 1,00 & 2,00 \\
Oppo F7 & 1,00 & 1,00 & 4,00 & 5,00 \\
Xiaomi Mi Max & 1,00 & 0,25 & 1,00 & 2,00 \\
$\begin{array}{l}\text { Asus Zenfone Max } \\
\text { Plus (M1) }\end{array}$ & 0,50 & 0,20 & 0,50 & 1,00 \\
\hline \multicolumn{1}{c}{ Total } & 3,50 & 2,45 & 6,50 & 10,00 \\
\hline
\end{tabular}

Setelah diperoleh PCM untuk kriteria harga, matriks dinormalisasikanmenggunakan cara yang sama dalam tabel 2 dengan membagi setiap entri pada Tabel 9 dengan total masing-masing kriteria sebagai berikut :

Tabel 10 Normalisasi PCM

\begin{tabular}{lccccc}
\hline Kapasitas RAM & Vivo V9 & Oppo F7 & $\begin{array}{c}\text { Xiaomi Mi } \\
\text { Max 2 }\end{array}$ & $\begin{array}{c}\text { Asus Zenfone } \\
\text { Max Plus (M1) }\end{array}$ & $\begin{array}{c}\text { Row } \\
\text { Average }\end{array}$ \\
\hline Vivo V9 & 0,29 & 0,41 & 0,15 & 0,20 & 0,26 \\
Oppo F7 & 0,29 & 0,41 & 0,62 & 0,50 & 0,45 \\
Xiaomi Mi Max 2 & 0,29 & 0,10 & 0,15 & 0,20 & 0,19 \\
Asus Zenfone & 0,14 & 0,08 & 0,08 & 0,10 & 0,10 \\
Max Plus (M1) & 1,00 & 1,00 & 1,00 & 1,00 & 1,00 \\
\hline \multicolumn{1}{c}{ Total } & 1,00
\end{tabular}

Dari Tabel 4.10. diperoleh bobot prioritas (row average) untuk masing-masing alternative terhadap kriteria kapasitas RAM dalam pemilihan smartphone android, yaitu Vivo V9 sebesar 0,26, Oppo F7 sebesar 0,45, Xiaomi Mi Max 2 sebesar 0,19, dan Asus Zenfone Max Plus (M1) sebesar 0,10. Jika sudah diperoleh nilai dari masing-masing kriteria, langkah berikutnya yakni menguji konsistensi dan menghitung (weighted Sum Vector Consistency) kemudian mencari nilai $\lambda$, CI dan CR. Weighted Sum Vector Consistency (WSV) diperoleh dengan cara sebagai berikut :Weighted Sum Vector Consistency (Tabel 9 x Row average Tabel 10)

$\left[\begin{array}{l}1,001,001,002,00 \\ 1,001,004,005,00 \\ 1,000,251,002,00 \\ 0,500,200,501,00\end{array}\right]\left[\begin{array}{l}0,26 \\ 0,45 \\ 0,19 \\ 0,10\end{array}\right]=\begin{array}{r}1,10 \\ 1,96 \\ 0,76 \\ 0,41\end{array}$

Setelah matriks WSV sudah didapatkan kemudian akan dihitung nilai dari Consistency Vector

$\left[\begin{array}{l}1,10 / 0,26 \\ 1,96 / 0,45 \\ 0,76 / 0,19 \\ 0,41 / 0,10\end{array}\right]=\left[\begin{array}{l}4,20 \\ 4,33 \\ 4,11 \\ 4,13\end{array}\right]$

Setelah consistency Vector sudah ditemukan, maka akandicari nilai $\lambda$ yakni dengan menjumlah consistency vector kemudian dibagi nilai $\mathrm{n}$, dimana $n$ adalah rasio 
matriks yang bersangkutan. $\lambda=\frac{\sum \text { consistency wector }}{n}=\frac{16,76}{4}=4,19$. Setelah nilai $\lambda$ sudah ditemukan maka berikut mencari nilai CI dan CR dan dapat mengetahui konsistensi dari data yang sudah diperoleh. $\mathrm{CI}=\frac{\lambda-\mathrm{n}}{n-1}=\frac{4,19-4}{4-1}=\frac{0,19}{4}=0,06$. Langkah selanjutnya $\mathrm{CR}$ dihitung dengan membagi nilai CI oleh RI yaitu Ratio Indeks yang diperoleh pada tabel RI. Besarkan RI untuk $\mathrm{n}=4$ adalah $0,90 . \mathrm{CR}=\frac{\mathrm{CI}}{R I}=\frac{0,06}{0,90}=0,07$. Nilai dari CR yang sudah didapatkan $\leq 0,1$ artinya data sudah konsisten. Maka bisa disimpulkan bahwa kapasitas RAM yang dipilih dalam pemilihan smartphone Vivo V9 sebesar 26\%,Oppo F7sebesar 45\%, Xiaomi Mi Max 2 sebesar 19\%, dan Asus Zenfone Max Plus (M1) sebesar 10\%.

\subsection{Perhitungan Pembobotan Komponen untuk Kriteria Sensor Lock}

Analisis ini dilakukan agar dapat mengetahui tingkatan dari prioritas masingmasing alternative pada kriteria sensor lock dalam pemilihan smartphone android. Hasil dari pembobotan masing-masing alternative yang didapatkan, diolah kemudian dimasukkan kedalam tabel PCM dengan rumus yang sama dengan Tabel 1 seperti terlihat pada Tabel 11 berikut

Tabel 11 PCM untuk Kriteria Sensor Lock

\begin{tabular}{lcccc}
\hline \multicolumn{1}{c}{ Sensor Lock } & Vivo V9 & Oppo F7 & $\begin{array}{c}\text { Xiaomi Mi Max } \\
2\end{array}$ & $\begin{array}{c}\text { Asus Zenfone Max Plus } \\
\text { (M1) }\end{array}$ \\
\hline Vivo V9 & 1,00 & 0,36 & 1,00 & 3,00 \\
Oppo F7 & 1,00 & 0,36 & 2,00 & 4,00 \\
Xiaomi Mi Max & 1,00 & 0,18 & 1,00 & 2,00 \\
$\begin{array}{l}\text { Asus Zenfone } \\
\text { Max Plus (M1) }\end{array}$ & 0,33 & 0,09 & 0,50 & 1,00 \\
\hline \multicolumn{1}{c}{ Total } & 3,33 & 2,75 & 4,50 & 10,00 \\
\hline
\end{tabular}

Setelah diperoleh PCM untuk kriteria sensor lock, matriks dinormalisasikan menggunakan cara yang sama dalam tabel 2 dengan membagi setiap entri pada Tabel 11 dengan total masing-masing kriteria sebagai berikut :

Tabel 12 Normalisasi PCM

\begin{tabular}{lccccc}
\hline \multicolumn{1}{c}{ Sensor Lock } & Vivo V9 & Oppo F7 & $\begin{array}{c}\text { Xiaomi Mi Max } \\
2\end{array}$ & $\begin{array}{c}\text { Asus Zenfone } \\
\text { Max Plus (M1) }\end{array}$ & $\begin{array}{c}\text { Row } \\
\text { Average }\end{array}$ \\
\hline Vivo V9 & 0,30 & 0,36 & 0,22 & 0,30 & 0,30 \\
Oppo F7 & 0,30 & 0,36 & 0,44 & 0,40 & 0,38 \\
Xiaomi Mi Max 2 & 0,30 & 0,18 & 0,22 & 0,20 & 0,23 \\
Asus Zenfone & 0,10 & 0,09 & 0,11 & 0,10 & 0,10 \\
Max Plus (M1) & 1,00 & 1,00 & 1,00 & 1,00 & 1,00 \\
\hline \multicolumn{1}{c}{ Total } & & & & & \\
\hline
\end{tabular}


Dari Tabel 12 diperoleh bobot prioritas (row average) untuk masing-masing alternative terhadap kriteria sensor lock dalam pemilihan smartphone android, yaitu Vivo V9 sebesar 0,30, Oppo F7 sebesar 0,38, Xiaomi Mi Max 2 sebesar 0,23, dan Asus Zenfone Max Plus (M1) sebesar 0,10. Jika sudah diperoleh nilai dari masing-masing kriteria, langkah berikutnya yakni menguji konsistensi dan menghitung (weighted Sum Vector Consistency) kemudian mencari nilai $\lambda$, CI dan CR. Weighted Sum Vector Consistency (WSV) diperoleh dengan cara sebagai berikut : Weighted Sum Vector Consistency (Tabel 11 x Row average Tabel 12)

$\left[\begin{array}{l}1,000,360,220,30 \\ 1,000,360,440,40 \\ 1,000,180,220,20 \\ 0,330,090,110,10\end{array}\right]\left[\begin{array}{l}0,30 \\ 0,38 \\ 0,23 \\ 0,10\end{array}\right] \begin{array}{r}1,20 \\ 1,53 \\ 0,91 \\ 0,41\end{array}$

Setelah matriks WSV sudah didapatkan kemudian akan dihitung nilai dari Consistency Vector

$\left[\begin{array}{l}1,20 / 0,30 \\ 1,53 / 0,38 \\ 0,91 / 0,23 \\ 0,41 / 0,10\end{array}\right]=\left[\begin{array}{l}4,05 \\ 4,04 \\ 4,04 \\ 4,05\end{array}\right]$

Setelah consistency Vector sudah ditemukan, maka akandicari nilai $\lambda$ yakni dengan menjumlah consistency vector kemudian dibagi nilai $\mathrm{n}$, dimana $n$ adalah rasio matriks yang bersangkutan. $\lambda=\frac{\sum \text { consistency vector }}{n}=\frac{16,18}{4}=4,05$. Setelah nilai $\lambda$ sudah ditemukan maka berikut mencari nilai CI dan CR dan dapat mengetahui konsistensi dari data yang sudah diperoleh. $\mathrm{CI}=\frac{\lambda-n}{n-1}=\frac{4,05-4}{4-1}=\frac{0,05}{3}=0,02$. Langkah selanjutnya $\mathrm{CR}$ dihitung dengan membagi nilai CI oleh RI yaitu Ratio Indeks yang diperoleh pada tabel RI. Besarkan RI untuk $\mathrm{n}=4$ adalah $0,90 . \mathrm{CR}=\frac{\mathrm{CI}}{R I}=\frac{0,02}{0,90}=0,02$. Nilai dari $\mathrm{CR}$ yang sudah didapatkan $\leq 0,1$ artinya data sudah konsisten. Maka bisa disimpulkan bahwa sensor lock yang dipilih dalam pemilihan smartphone Vivo V9 sebesar 30\%, Oppo F7 sebesar 38\%, Xiaomi Mi Max 2 sebesar 23\%, dan Asus Zenfone Max Plus (M1) sebesar 10\%.

\section{3) Menyusun Matriks Keputusan}

Setelah diperoleh tingkat prioritas dari setiap alternative terhadap masing-masing kriteria dalam pemilihan smartphone android, maka dapat disusun matriks keputusan. Matriks keputusan diperoleh dengan cara memasukkan semua vektor eigen atau row average yang telah dihitung ke dalam sebuah matriks yang sesuai dengan selnya sehingga diperoleh hasil sebagai berikut : 
Tabel 13 Matriks Keputusan

\begin{tabular}{lccccc}
\hline \multirow{2}{*}{ Alternatif } & \multicolumn{5}{c}{ Kriteria } \\
\cline { 2 - 5 } & Harga & $\begin{array}{c}\text { Kualitas } \\
\text { Jaringan }\end{array}$ & $\begin{array}{c}\text { Kapasitas } \\
\text { Memori }\end{array}$ & Kapasitas RAM & Sensor Lock \\
\hline Vivo V9 & 0,37 & 0,30 & 0,34 & 0,26 & 0,30 \\
Oppo F7 & 0,37 & 0,39 & 0,31 & 0,45 & 0,38 \\
Xiaomi Mi Max 2 & 0,15 & 0,21 & 0,15 & 0,19 & 0,23 \\
Asus Zenfone Max & 0,11 & 0,11 & 0,20 & 0,10 & 0,10 \\
Plus (M1) & & & & \\
\hline
\end{tabular}

Tabel 13 mempunyai arti bahwa vektor eigen untuk kriteria harga pada Vivo V9 sebesar 37\%, Oppo F7 sebesar 37 \%, Xiaomi Mi Max 2 sebesar 15\%, dan Asus Zenfone Max Plus (M1) sebesar 11\%. Semua vektor eigen yang sudah didapat pada proses perhitungan masing-masing alternatif pada setiap kriteria dituliskan ke dalam sel matriks yang saling bersesuaian sehingga akan diperoleh matriks keputusan.

\subsection{Matriks Keputusan Ternormalisasi}

Matriks keputusan yang sudah dibuat selanjutnya dinormalisasikan supaya setiap vektor dari masing-masing kriteria mempunyai panjang yang sama. Matriks keputusan dapat dinormalisasikan dengan rumus berikut $: r_{i j}=\frac{x_{i j}}{\sqrt{\sum_{i=1}^{m} x_{i j}^{2}}}, \mathrm{i}=1,2, \ldots \mathrm{m}, \mathrm{j}=1,2 \ldots ., \mathrm{m}$

Tabel 14 Matriks Keputusan

\begin{tabular}{|c|c|c|c|c|c|}
\hline Alternatif & Harga & $\begin{array}{l}\text { Kualitas } \\
\text { Jaringan }\end{array}$ & $\begin{array}{c}\text { Kapasitas } \\
\text { Memori }\end{array}$ & Kapasitas RAM & Sensor Lock \\
\hline Vivo V9 & 0,37 & 0,30 & 0,34 & 0,26 & 0,30 \\
\hline Oppo F7 & 0,37 & 0,39 & 0,31 & 0,45 & 0,38 \\
\hline Xiaomi Mi Max 2 & 0,15 & 0,21 & 0,15 & 0,19 & 0,23 \\
\hline $\begin{array}{l}\text { Asus Zenfone } \\
\text { Max Plus (M1) }\end{array}$ & 0,11 & 0,11 & 0,20 & 0,10 & 0,10 \\
\hline
\end{tabular}

dan seterusnya, sehingga dapat dihasilkan matriks keputusan ternormalisasi pada tabel berikut :

Tabel 15 Matriks Keputusan Ternormalisasi

\begin{tabular}{lccccc}
\hline \multirow{2}{*}{ Alternatif } & Harga & $\begin{array}{c}\text { Kualitas } \\
\text { Jaringan }\end{array}$ & $\begin{array}{c}\text { Kapasitas } \\
\text { Memori }\end{array}$ & $\begin{array}{c}\text { Kapasitas } \\
\text { RAM }\end{array}$ & Sensor Lock \\
\cline { 2 - 5 } & 0,67 & 0,55 & 0,64 & 0,46 & 0,55 \\
Vivo V9 & 0,67 & 0,72 & 0,60 & 0,80 & 0,70 \\
Oppo F7 & 0,27 & 0,38 & 0,28 & 0,33 & 0,42 \\
Xiaomi Mi Max 2 & 0,19 & 0,20 & 0,39 & 0,18 & 0,19 \\
Asus Zenfone & 0,19 &
\end{tabular}

\subsection{Perhitungan Matriks Keputusan Ternormalisasi Terbobot}

Langkah berikutnya setelah matriks keputusan ternormalisasi sudah didapatkan yakni menghitung matriks keputusan ternormalisasi terbobot. Matriks keputusan ternormalisasi terbobot dapat diperoleh dengan mengalikan masing-masing kolom elemen 
matriks keputusan ternormalisasi oleh bobot preferensi setiap kriteria yaitu $\mathrm{W}=(0,33$ $0,320,18 \quad 0,11 \quad 0,06)$, maka akan diperoleh matriks sebagai berikut :

$y_{11}=w_{1} r_{11}=(0,67)(0,33)=0,22$

$y_{12}=w_{2} r_{12}=(0,55)(0,32)=0,18$

$y_{13}=w_{3} r_{13}=(0,64)(0,18)=0,11$

$y_{14}=w_{4} r_{14}=(0,46)(0,11)=0,05 ;$ dan seterusnya. Sehingga dihasilkan matriks

keputusan ternormalisasi terbobot sebagai berikut

Tabel 16 Matriks Keputusan Ternormalisasi Terbobot

\begin{tabular}{lccccc}
\hline \multirow{2}{*}{ Alternatif } & Karga & $\begin{array}{c}\text { Kualitas } \\
\text { Jaringan }\end{array}$ & $\begin{array}{c}\text { Kapasitas } \\
\text { Memori }\end{array}$ & Kapasitas RAM & Sensor Lock \\
\cline { 2 - 5 } & 0,22 & 0,18 & 0,11 & 0,05 & 0,03 \\
\hline Vivo V9 & 0,22 & 0,23 & 0,11 & 0,09 & 0,04 \\
Oppo F7 & 0,09 & 0,12 & 0,05 & 0,04 & 0,02 \\
Xiaomi Mi Max 2 & 0,06 & 0,06 & 0,07 & 0,02 & 0,01 \\
Asus Zenfone & & & & 0.02 \\
Max Plus (M1) & & &
\end{tabular}

\section{4) Menentukan Solusi Ideal Positif dan Solusi Ideal Negatif}

"Matriks ternormalisasi terbobot yang telah diperoleh, digunakan untuk menentukan SIP (solusi ideal positif). SIP diperoleh dengan mencari nilai maksimum dari semua alternatif terhadap setiap masing-masing kriteria pada matriks ternormalisasi terbobot, jika kriteria tersebut merupakan kriteria keuntungan dimana nilai terbesar adalah nilai terbaik." (Defit, 2017)

"Sebaliknya, SIP diperoleh dengan mencari nilai minimum dari semua alternatif terhadap setiap masing-masing kriteria pada matriks ternormalisasi terbobot, jika ktiteria tersebut merupakan biaya dimana nilai terbesar merupakan nilai terburuk. Karena kriteria yang telah ditetapkan merupakan kriteria keuntungan maka yang akan dilakukan adalah mencari nilai maksimum dari semua alternative terhadap masing-masing kriteria sehingga diperoleh sebagai berikut" (Defit, 2017):

$y_{1}^{+}=\max (0,22 ; 0,22 ; 0,09 ; 0,06)=0,22$

$$
\begin{aligned}
& y_{2}^{+}=\max (0,18 ; 0,23 ; 0,12 ; 0,06)=0,23 \\
& y_{3}^{+}=\max (0,11 ; 0,11 ; 0,05 ; 0,07)=0,11 \\
& y_{4}^{+}=\max (0,05 ; 0,09 ; 0,04 ; 0,02)=0,09
\end{aligned}
$$

$y_{5}^{+}=\max (0,03 ; 0,04 ; 0,02 ; 0,01)=0,04$. Sehingga dihasilkan solusi ideal positif sebagai berikut :

Tabel 17 Solusi Ideal Positif 


\begin{tabular}{cccccc}
\hline & & Jaringan & Memori & RAM & Lock \\
\hline Nilai Maksimum $\left(A^{+}\right)$ & 0,22 & 0,23 & 0,11 & 0,09 & 0,04 \\
\hline "Matriks ternormalisasi terbobot
\end{tabular}

"Matriks ternormalisasi terbobot yang telah diperoleh, digunakan untuk menentukan SIN (Solusi Ideal Negatif). SIN diperoleh dengan mencari nilai minimum dari semua alternatif terhadap setiap masing-masing kriteria pada matriks ternormalisasi terbobot, jika kriteria tersebut merupakan kriteria keuntungan dimana nilai terbesar adalah nilai terbaik." (Defit, 2017)

"Sebaliknya, matriks SIN diperoleh dengan mencari nilai maksimum dari semua alternatif terhadap setiap masing-masing kriteria pada matriks ternormalisasi terbobot, jika kriteria tersebut merupakan biaya dimana nilai ditetapkan merupakan kriteria keuntungan maka yang akan dilakukan adalah mencari nilai minimum dari semua alternative terhadap masing-masing kriteria sehingga diperoleh sebagai berikut" (Defit, 2017) :

$y_{1}^{-}=\max (0,22 ; 0,22 ; 0,09 ; 0,06)=0,06$

$y_{2}^{-}=\max (0,18 ; 0,23 ; 0,12 ; 0,06)=0,06$

$y_{3}^{-}=\max (0,11 ; 0,11 ; 0,05 ; 0,07)=0,05$

$y_{4}^{-}=\max (0,05 ; 0,09 ; 0,04 ; 0,02)=0,02$

$y_{5}^{-}=\max (0,03 ; 0,04 ; 0,02 ; 0,01)=0,01$. Sehingga dihasilakan solusi ideal negative sebagai berikut :

Tabel 18 Solusi Ideal Negatif

\begin{tabular}{cccccc}
\hline Kriteria & Harga & $\begin{array}{c}\text { Kualitas } \\
\text { Jaringan }\end{array}$ & $\begin{array}{c}\text { Kapasitas } \\
\text { Memori }\end{array}$ & $\begin{array}{c}\text { Kapasitas } \\
\text { RAM }\end{array}$ & $\begin{array}{c}\text { Sensor } \\
\text { Lock }\end{array}$ \\
\hline Nilai Minimmum $\left(A^{-}\right)$ & 0,06 & 0,06 & 0,05 & 0,02 & 0,01 \\
\hline
\end{tabular}

\section{5) Menghitung Separasi}

Setelah SIP sudah diperoleh maka akan dihitung separasi dari masing-masing alternatif agar mendapatkan jarak pendekatan dari masing-masing alternative terhadap SIP. Separasi terhadap SIP diperoleh dengan rumus sebagai berikut:

$$
\begin{aligned}
& S_{i}^{+}=\sqrt{\sum_{j=1}^{n}\left(y_{i j}-y_{j}^{+}\right)^{2}}, \mathrm{i}=1,2,3, \ldots, \mathrm{m} \\
& S_{1}^{+}=\sqrt{(0,22-0,22)^{2}+(0,18-0,23)^{2}+(0,11-0,11)^{2}+(0,05-0,09)^{2}+(0,03-0,44)^{2}}=0,07 ;
\end{aligned}
$$

dan seterusnya, sehingga dihasilkan solusi ideal positif sebagai berikut :

\begin{tabular}{|c|c|}
\hline Alternatif & Jarak terhadap SIP \\
\hline Vivo V9 & 0,07 \\
\hline
\end{tabular}

\section{Tabel 19 Hasil Perhitungan Separasi Solusi Ideal Positif}


Oppo F7

0,01

Xiaomi Mi Max 2

0,19

Asus Zenfone Max Plus (M1)

0,24

Tabel 19 tersebut memiliki arti bahwa smartphone Oppo F7 memiliki jarak terdekat dengan SIP dalam menentukan pemilihan smartphone android sebesar 0,01 diikuti oleh VivoV9 Sebesar 0,07, Xiaomo Mi Max 2 sebesar 0,19 dan Asus Zenfone Max Plus (M1) sebesar 0,24.

Setelah SIN sudah diperoleh maka akan dihitung separasi dari masing-masing alternatif agar mendapatkan jarak pendekatan dari masing-masing alternative terhadap SIN. Separasi terhadap SIN diperoleh dengan rumus sebagai berikut:

$S_{i}^{-}=\sqrt{\sum_{j=1}^{n}\left(y_{i j}-y_{j}^{-}\right)^{2}}, \mathrm{i}=1,2,3, \ldots, \mathrm{m}$

$S_{1}^{-}=\sqrt{(0,22-0,06)^{2}+(0,18-0,06)^{2}+(0,11-0,05)^{2}+(0,05-0,02)^{2}+(0,03-0,01)^{2}}=0,21 ；$

dan seterusnya, sehingga dihasilkan solusi ideal negatif sebagai berikut :

Tabel 20 Hasil Perhitungan Separasi Solusi Ideal Negatif

\begin{tabular}{lc}
\hline \multicolumn{1}{c}{ Alternatif } & Jarak terhadap SIN \\
\hline Vivo V9 & 0,21 \\
Oppo F7 & 0,25 \\
Xiaomi Mi Max 2 & 0,07 \\
Asus Zenfone Max Plus (M1) & 0,02 \\
\hline
\end{tabular}

Tabel 20 tersebut memiliki arti bahwa smartphone Oppo F7 memiliki jarak terjauh dengan SIN dalam menentukan pemilihan smartphone android sebesar 0,25 diikuti oleh VivoV9 Sebesar 0,21, Xiaomo Mi Max 2 sebesar 0,07 dan Asus Zenfone Max Plus (M1) sebesar 0,02

6) Menghitung Nilai Preferensi dan Menentukan Smartphone Android yang Tepat.

Langkah yang terakhir dari analisis pemilihan smarthphone android yakni menghitung nilai preferensi, dimana smartphone android yang memiliki preferensi yang paling besar adalah smartphone yang terpilih. Menghitung nilai preferensi atau jarak kedekatan relatif dilakukan dengan cara membagi setiap jarak alternatif terhadap SIN dengan jumlah jarak alternatif terhadap SIP dan jarak alternatif terhadap SIN. Sedemikian sehingga diperoleh sebagai berikut :
$C_{1}=\frac{0,21}{0,21+0,07}=0,77$,
$C_{2}=\frac{0,25}{0,25+0,01}=0,98$,
$C_{3}=\frac{0,07}{0,07+0,19}=0,28$,
$C_{4}=\frac{0,02}{0,02+0,24}=0,17$

Tabel 21 Nilai Preferensi

\begin{tabular}{ccc} 
& Alternatif & Nilai Preferensi \\
\hline Vivo V9 & 0,77
\end{tabular}




$\begin{array}{ll}\text { Oppo F7 } & 0,98 \\ \text { Xiaomi Mi Max 2 } & 0,28 \\ \text { Asus Zenfone Max Plus (M1) } & 0,17\end{array}$

\section{KESIMPULAN DAN SARAN}

Dari hasil penelitian dan pembahasan dapat disimpulkan sebagai berikut:

1. Kriteria yang menjadi prioritas dalam pemilihan tipe smarphone android terbaik adalah kriteria harga dengan bobot sebesar 33\%, kriteria dengan kulaitas jaringan dengan bobot sebesar $32 \%$, kriteria kapasitas memori dengan bobot sebesar $18 \%$, kriteria kapasitas ram dengan bobot sebesar $11 \%$, dan sensor lock dengan bobot sebesar 6\%.

2. Nilai matriks yang diperoleh untuk pemilihan smarphone android terbaik adalah :

1) Harga : android Vivo V9 dengan bobot sebesar 37\%, Oppo F7 dengan bobot sebesar 37\%, Xiaomi Mi Max dengan bobot sebesar 15\%,dan Asus Zenfone Max Plus M1 dengan bobot sebesar $11 \%$.

2) Kualitas Jaringan : android Vivo V9 dengan bobot sebesar 30\%, Oppo F7 dengan bobot sebesar 29\%, Xiaomi Mi Max dengan bobot sebesar 21\%,dan Asus Zenfone Max Plus M1 dengan bobot sebesar 11\%.

3) Kapasitas memori : android Vivo V9 dengan bobot sebesar 34\%, Oppo F7 dengan bobot sebesar 31\%, Xiaomi Mi Max dengan bobot sebesar 15\%,dan Asus Zenfone Max Plus M1 dengan bobot sebesar $20 \%$.

4) Kapasitas RAM : android Vivo V9 dengan bobot sebesar 26\%, Oppo F7 dengan bobot sebesar 45\%, Xiaomi Mi Max dengan bobot sebesar 19\%,dan Asus Zenfone Max Plus M1 dengan bobot sebesar $10 \%$.

5) Sensor Lock : android Vivo V9 dengan bobot sebesar $55 \%$, Oppo F7 dengan bobot sebesar 70\%, Xiaomi Mi Max dengan bobot sebesar 42\%,dan Asus Zenfone Max Plus M1 dengan bobot sebesar 19\%.

3. Smarphone android yang memiliki jarak terdekat dengan solusi ideal positif adalah Oppo F7 dengan bobot sebesar 0,01 yang memiliki jarak terjauh dengan solusi ideal positif adalah Asus Zenfone Max Plus M1 dengan bobot sebesar 0,24

4. Smarphone android yang memiliki jarak terdekat dengan solusi ideal negative adalah Oppo F7 dengan bobot sebesar 0,25 dan yang memiliki jarak terjauh dengan solusi ideal negative adalah Asus Zenfone Max Plus MI dengan bobot sebesar 0,02

5. Nilai preferensi terbesar diperoleh Oppo F7 dengan nilai sebesar 0,98 kemudian di ikuti oleh Vivo V9 dengan nilai sebesar 0,77, Xiaomi Mi Max dengan nilia sebesar 0,28, dan Asus Zenfone Max Plus MI dengan nilai sebesar 0,17. sehingga Oppo F7 merupakan smartphone android terbaik.

Saran untuk peneliti selanjutnya untuk membuat aplikasi sistem pendukung keputusan (SPK) untuk metode Technique for Order Preference by Similarity to Ideal Solution (TOPSIS), agar mempercepat dalam mengambil keputusan

\section{DAFTAR PUSTAKA}

Defit, S. (2017). Multi Criteria Decision Making (MCDM). Medan: Deeplublish

Maulana, W. Z. (2016). Pengembangan Sistem Pendukung Keputusan Penerimaan karyawan Menggunakan Metode ANP-TOPSIS. Semarang: Unnes

Pratiwi, H. (2016). Sistem Pendukung Keputusan. Samarinda: Deepublish 